\title{
A PROSPECTIVE STUDY OF DENTAL DISEASE PATTERN AND DRUG UTILIZATION AT THE DENTAL DEPARTMENT OF A TERTIARY CARE TEACHING HOSPITAL IN EASTERN NEPAL
}

\section{ABSTRACT}

\author{
Rauniar $\mathbf{G} \mathbf{P}^{1}$, Shahanas $\mathbf{M} \mathbf{S}^{2}$ \\ Das B P $\mathbf{P}^{3}$, Naga Rani M A
}

To find out the pattern of dental diseases and drug utilization at dental out patient department (OPD) of B.P. Koirala Institute of Health Sciences (BPKIHS), a tertiary care hospital. A prospective prescription audit was conducted for a period of 10 days in the dental OPD and the data was analyzed using WHO drug indicators. The total number of prescriptions analyzed were 279 . Dental caries (37\%), Periodontitis (14\%) and chronic gingivitis $(11 \%)$ were the most common diseases with a maximum incidence between the age groups of 9 to 40 years. Mean number of drugs per prescription was 2.79. Of the total prescriptions, $223(79.9 \%)$ had 314 antimicrobial agents (AMA) constituting $40.3 \%$ of total drugs prescribed. The mean number of antimicrobial agents per prescription was 1.13 . The most commonly prescribed antimicrobial agents was amoxycillin $(33.1 \%)$ followed by metronidazole $(24.9 \%)$, doxycycline $(\mathbf{1 7 . 2 \%})$ and tinidazole $(12.7 \%)$. Fixed dose drug combination of amoxycillin + cloxacillin (26) and ampicillin + cloxacillin (10) were prescribed in 36 of the prescriptions. Povidone iodine gargle $(\mathbf{4 1 . 2 \%})$ was the most commonly prescribed oropharyngeal preparation followed by Chlorhexidine gluconate mouthwash $(32.4 \%)$. Non- steroidal anti-inflammatory agents $(\mathbf{2 0 . 6 6 \%})$, multi-vitamins $(\mathbf{1 9 . 5 1 \% )}$ ) and oropharyngeal preparations $(\mathbf{1 7 . 4 5 \% )}$ constituted the rest of the drugs prescribed. Diclofenac $(60.86 \%)$ was the most commonly prescribed among NSAIDs and fixed dose drug combination of ibuprofen and paracetamol was prescribed in 19 of the prescriptions. All drugs were given by oral route (except for gentamicin in one prescription) and were prescribed under brand names. None of the prescriptions had instructions whether the drug should be taken before or after food. The results indicate that dental caries was the most common dental disease, anti-microbial agents were prescribed to majority of the patients and constituted a little less than half of the total drugs prescribed. Commonly used antimicrobial agent was amoxycillin which in two thirds of the cases was prescribed as an fixed dose drug combination. The high incidence of anti-microbial agent prescribing may be modified by a feedback to the prescribers.

Key words: Dental morbidity, prescribing pattern, drug utilization, dental OPD, antimicrobial agents.

1. Dept. of Pharmacology, BPKIHS, Dharan, Nepal.

2. Dental Surgeon, Dental College, BPKIHS, Dharan, Nepal.

3. Associate Professor, Dept. of Pharmacology, BPKIHS, Dharan, Nepal.

4. Professor \& Head, Dept. of Pharmacology, BPKIHS, Dharan, Nepal.

Address for correspondence : $\quad$ Dr. G.P. Rauniar, Dept. of Pharmacology

B.P. Koirala Institute of Health Sciences, Dharan, Nepal.

Ph. No. :977-25-25555-3243 (Res.), 2483 (Off.), Fax: 977-25-20251

Email: gprauniar@hotmail.com 


\section{INTRODUCTION}

A high incidence of dental diseases in Kathmandu was reported by Basnyat et al $(1991)^{1}$. There was an extensive report and the population studied was from two schools and from the out patient department (OPD) of Tribhuvan University Teaching Hospital. The study provided valid information on the incidence of dental morbidity and guidelines for reducing the incidence of dental diseases. Though there have been quite a few studies ${ }^{2 \cdot 3}$ from western countries on drug utilization in dental departments no such studies were conducted in Nepal. Hence, this present study was undertaken with an aim to develop baseline data on drug prescribing pattern and provide feedback to the dentists to enable them to rationalize their prescribing practices.

\section{MATERIALS AND METHODS}

Data from prescriptions collected at random from the dental out-patient department of BPKIHS was recorded by the investigators on specially designed proforma for a period of ten days starting from 2.3.1998 to 12.3.1998. The data collected included name, age, sex, indications (diagnosis), drug name, dose, route of administration, frequency and duration of treatment. Drugs administered for treating the dental pathology only were counted. Each drug prescribed was counted as one and the number of prescriptions containing a drug was used to express the prescribing frequency of that drug. Local anaesthetics administered for dental extraction were not counted as drugs. Data was analyzed to find out the pattern of dental diseases and prescribing pattern using WHO drug indicators. ${ }^{4}$

\section{RESULTS}

A total of 279 prescriptions were analysed and data was tabulated.
Table I. Incidence of Dental Diseases in Male and Female Patients Attending Dental Out Patients Department

\begin{tabular}{|c|c|c|c|}
\hline $\begin{array}{c}\text { Age } \\
\text { (year) }\end{array}$ & Male & Female & Total (\%) \\
\hline$<8$ & 15 & 12 & $27(9.67)$ \\
$9-20$ & 31 & 25 & $56(20.10)$ \\
$21-30$ & 32 & 55 & $87(31.18)$ \\
$31-40$ & 15 & 32 & $47(16.84)$ \\
$41-50$ & 18 & 12 & $30(10.75)$ \\
$51-60$ & 10 & 6 & $16(5.73)$ \\
$>60$ & 8 & 8 & $16(5.73)$ \\
\hline Total & $\mathbf{1 2 9}$ & $\mathbf{1 5 0}$ & $\mathbf{2 7 9}$ \\
\hline
\end{tabular}

Table I shows the incidence of dental diseases in different age groups. The number of female and male patients who attended the OPD was 150 $(53.76 \%)$ and $129(46.24 \%)$ respectively. In this population visiting the hospital OPD, the dental diseases were more common in the age group of 9$40 \mathrm{yr}$ who constituted $68 \%$ (190) of the total patients. Fig.1 shows that the commonest dental

Figure 1: Pattern of Dental Diseases (n-279)

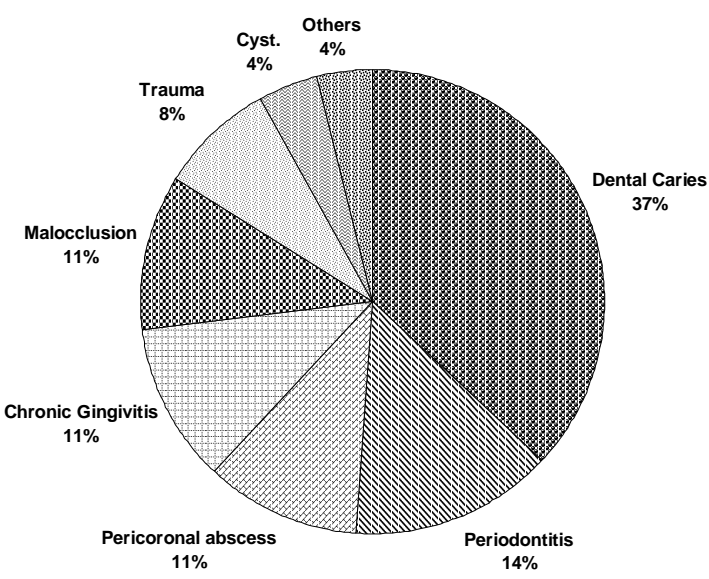

diseases were dental caries (37\%), periodontitis (14\%), pericoronal abscess $(11 \%)$ and chronic gingivitis (11\%).

The 279 prescriptions had 779 drugs and the number of mean drugs per prescription was 2.79(Table II). About 60\% (166/279) of the prescriptions had 3-5 drugs while 20\% (56/279) 
Table II. Data on prescribing pattern in Dental out Patient Department

\begin{tabular}{|l|c|}
\hline & No. (\%) \\
\hline Total no. of prescriptions & 279 \\
\hline Total number of drugs prescribed & 779 \\
\hline Mean no. of drugs prescribed & 2.79 \\
\hline Total no. of AMA* prescribed & $314(40.30)$ \\
\hline Total no. of prescriptions with AMA* & $223(79.9)$ \\
\hline Mean no. of AMA* / prescription & 1.13 \\
\hline $\begin{array}{l}\text { Total no. of oro-pharyngeal } \\
\text { preparations prescribed }\end{array}$ & $136(17.45)$ \\
\hline $\begin{array}{l}\text { Total no. of prescriptions with oro- } \\
\text { pharyngeal preparations }\end{array}$ & $199(42.65)$ \\
\hline $\begin{array}{l}\text { Mean no. of oro-pharyngeal / } \\
\text { prescription }\end{array}$ & 0.49 \\
\hline Total no. of NSAIDs prescribed & $161(20.66)$ \\
\hline Total no. of prescriptions with NSAIDs & $161(57.70)$ \\
\hline Mean no. of NSAIDs / prescription & 0.58 \\
\hline Total no. of multi-vitamins prescribed & $152(19.51)$ \\
\hline $\begin{array}{l}\text { Total no. of prescriptions with multi- } \\
\text { vitamins }\end{array}$ & $152(54.48)$ \\
\hline $\begin{array}{l}\text { Number of drugs prescribed by generic } \\
\text { name }\end{array}$ & NIL \\
\hline No. of drugs prescribed as injections & $1(0.12)$ \\
\hline
\end{tabular}

* AMA = Antimicrobial Agents

of the prescriptions (Fig-2) had no drug as those were for dental filling. Table II provides a

Figure 2 : Incidence of Polypharmacy $(n=279)$

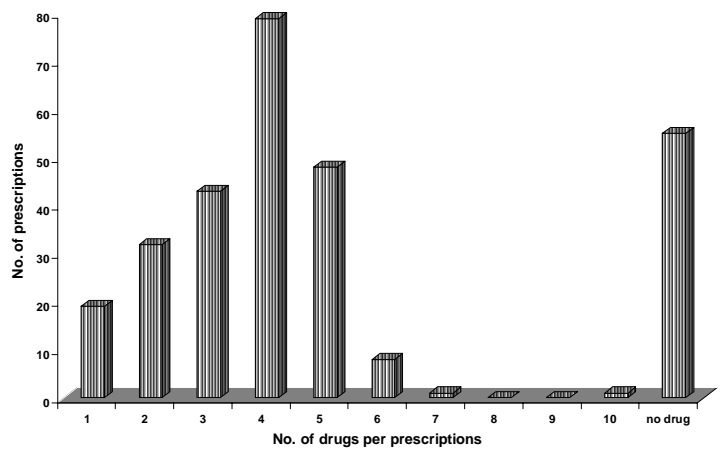

comprehensive data about the different drug groups prescribed and mean number of drugs per prescription in each drug group. It is clear from the table that very few drug groups were prescribed in dental diseases. Antimicrobial agents were the most commonly prescribed group (40.30\%) of drugs with a mean of 1.13 per prescription. The next most commonly prescribed drug group was NSAIDs (Non-steroidal anti-inflammatory drugs) which accounted for $20.66 \%$ with a mean drug of
0.58 per prescription. The other drug groups prescribed were multi-vitamins $(19.51 \%)$ and oropharyngeal preparations $(17.45 \%)$.

\section{Table III. Ten Most Commonly Prescribed Drugs $(\mathrm{n}=779)$}

\begin{tabular}{|c|l|c|}
\hline S.N & \multicolumn{1}{|c|}{ Drug } & No. (\%) \\
\hline 1. & Multi- vitamins/minerals & $152(19.5)$ \\
2. & Amoxicillin & $104(13.4)$ \\
3. & Diclofenac & $98(12.6)$ \\
4. & Metronidazole & $78(10.0)$ \\
5. & Povidone iodine gargle & $56(7.2)$ \\
6. & Doxycycline & $54(6.9)$ \\
7. & Ibuprofen & $44(5.6)$ \\
8. & Chlorhexidine gluconate & $44(5.6)$ \\
9. & Amoxicillin+Cloxacillin & $26(3.3)$ \\
10. & Ibuprofen+ paracetamol & $19(2.4)$ \\
\hline
\end{tabular}

Perusal of table III. shows that vitamins (19.5\%), amoxicillin (13.4\%) and diclofenac (12.65\%) were the most commonly prescribed drugs.

Table IV. Pattern of Prescribing of AMA

\begin{tabular}{|c|l|c|c}
\hline S.N & $\begin{array}{c}\text { Antimicrobial agents } \\
\text { (AMA) }\end{array}$ & $\begin{array}{c}\text { Frequency of } \\
\text { prescribing(\%) } \\
(\mathbf{n = 2 7 9 )}\end{array}$ & $\begin{array}{c}\text { \% of total AMA } \\
\text { prescribed } \\
(\mathbf{n = 3 1 4})\end{array}$ \\
\hline 1. & Amoxycillin & $104(37.26)$ & 33.1 \\
\hline 2. & Metronidazole & $78(27.96)$ & 24.9 \\
\hline 3. & Doxycycline & $54(19.35)$ & 17.2 \\
\hline 4. & Tinidazole & $40(14.34)$ & 12.7 \\
\hline 5. & Amoxycillin+Cloxacillin & $26(9.32)$ & 8.3 \\
\hline 6. & Ampicillin+Cloxacillm & $10(3.59)$ & 3.2 \\
\hline 7. & Gentamicin* & $1(0.36)$ & 0.3 \\
\hline 8. & Minocycline & $1(0.36)$ & 0.3 \\
\hline
\end{tabular}

* Intramuscular

Table IV shows that amoxycillin (33.1\%), metronidazole (24.9\%), doxycycline $(17.2 \%)$ and tinidazole (12.7\%) were the most commonly prescribed antimicrobial agents. Thirty six of the prescriptions contained fixed-dose drug combination of amoxycillin + cloxacillin and ampicillin + cloxacillin. The 5 mean duration of prescription of antimicrobial agents both for prophylactic and therapeutic purposes was from 4.78 to 6.2 days. 
Table V. Pattern of Prescribing of

Oropharyngeal Preparations

\begin{tabular}{|c|l|c|c|}
\hline S.N & \multicolumn{1}{|c|}{ Name } & $\begin{array}{c}\text { Frequency of } \\
\text { prescribing } \\
\text { (n-136) }\end{array}$ & $\begin{array}{c}\text { \% of total } \\
\text { oropharyngeal } \\
\text { preparations } \\
\text { prescribed (n-136) }\end{array}$ \\
\hline 1. & Povidone iodine gargle & 56 & 41.2 \\
\hline 2. & $\begin{array}{l}\text { Chlorhexidine gluconate } \\
\text { mouthwash }\end{array}$ & 44 & 32.4 \\
\hline 3. & $\begin{array}{l}\text { Thymol. Eucolyptol, Benzoic } \\
\text { and Menthol }\end{array}$ & 14 & 10.3 \\
\hline 4. & Formaline Tooth paste & 13 & 9.5 \\
\hline 5. & Strontium chloride Tooth paste & 9 & 6.6 \\
\hline
\end{tabular}

Table V provides data on preparations for local antiseptics such as povidone iodine gargle $(41.2 \%)$, chlorhexidine gluconate $(32.4 \%)$, thymol + eucolyptol + benzoic acid + menthol mouth wash $(10.3 \%)$. The rest were special therapeutic type of tooth pastes containing formaline $(9.5 \%)$ and strontium $(6.6 \%)$.

\section{Table VI. Pattern of Prescribing of NSAIDS}

\begin{tabular}{|l|l|c|c|}
\hline S.N & NSAIDs & $\begin{array}{c}\text { Frequency } \\
\text { of } \\
\text { prescribing } \\
\text { (n-161) }\end{array}$ & $\begin{array}{c}\text { \% of total } \\
\text { NSAIDs } \\
\text { prescribed } \\
\text { (n-161) }\end{array}$ \\
\hline 1. & Diclofenac & 98 & 60.86 \\
\hline 2. & Ibuprofen & 44 & 27.32 \\
\hline 3. & $\begin{array}{l}\text { Ibuprofen + } \\
\text { Paracetamol }\end{array}$ & 19 & 11.80 \\
\hline
\end{tabular}

Table VI provides data on NSAIDs. Of the total number of prescriptions containing NSAIDs, 98 were for diclofenac, 44 for ibuprofen and 19 were for fixed dose drug combination of ibuprofen and paracetamol. None of the prescriptions had an advice for the patient to take NSAIDs after food.

\section{DISCUSSION}

The results of this study showed that the prevalence of dental caries and periodontis in eastern Nepal was high and is similar to that in Kathmandu ${ }^{1}$ and in India ${ }^{5}$. The high incidence of dental diseases in developing countries may be related to inadequate oral hygiene which is the result of rapid urbanization, low school attendance and lower rate of adult literacy ${ }^{6}$.

The mean number of drugs 2.79 per prescription in the dental OPD was comparable to that $(2.17$ drugs per prescription) observed in another pharmacy based study conducted in India ${ }^{7}$. The drug categories prescribed in dental OPD were very few and were appropriate. Anti-microbial agents formed the bulk of the prescribed drugs and the frequency of prescribing of anti -microbial agents (79.9\%) was considerably high. In our study, the drugs most commonly used were antimicrobial agents (40.30\%). The choice of Amoxycillin is justified as it reaches effective concentration in gingival crevicular fluid ${ }^{8}$. An advise to take ampicillin on empty stomach to enhance absorption ${ }^{9}$ would have increased the efficacy of the drug. Though tetracyclines were also shown to promote healing in periodontal disease by stabilizing collagen ${ }^{10}$, they suffer from the limitation that they are contraindicated in children and pregnant women. Most often therapeutic antibiotic selection was done on empirical basis and such practice of selection without culture and sensitivity may increase antimicrobial resistance and adverse drug reactions. But, in dental practice getting uncontaminated material for culture and sensitivity may not always be possible as also the prohibitive cost of culture and sensitivity. The American Heart Association has developed new antibiotic prophylaxis guidelines for dental professionals to decrease the risk of infective endocarditis ${ }^{12}$. It is highly essential that all dental practioners are aware of these guidelines and follow them. Though the anti-microbial agents prescribed were not newer expensive group of antibiotics, the very high frequency of prescribing may have to be discouraged as it increases the cost of therapy, adverse drug reactions and bacterial resistance. In the present study, metronidazole was the second 
most commonly prescribed anti-microbial agent. Muthukrishanan et al in a study conducted at New port found that general dental practitioners were reluctant to prescribe metronidazole as a first choice even in patients who were allergic to penicillin and they remarked that awareness about the use of antibiotics needs to be increased among general dental practitioners. ${ }^{13}$

NSAIDs are effective in controlling periodontal disease ${ }^{10}$ as they reduce breakdown of dental tissue ${ }^{14}$ and prescribing these to almost half of the patients visiting dental OPD may be justified. But, a written advice about taking them after food, would help in minimizing their side effects.

In our study, multivitamins were prescribed to the extent of $54.48 \%$ and formed $19.5 \%$ of the total drugs prescribed. Though their use is justified as rejuvenating agents even without a specific deficiency ${ }^{15}$, increased cost of treatment may be a burden on the patient. Such over prescription of vitamins may be the result of the aggressive promoting practices of the pharmaceutical agencies and/or patients' demand for them.

The demonstrated beneficial effect of chlorhexidine by local antiseptic action in the prevention of dental caries ${ }^{16}$ justified its prescription in the present study.

Fixed dose drug combinations also were prescribed generally to a large extent. All the drugs were prescribed only by brand name and generic names were not used. Prescription by brand names increases the cost of the treatment and this may be brought down by prescribing generic preparations which are more cost-effective. Development of a hospital formulary, making available drugs in the hospital pharmacy, model treatment guidelines, may increase the prescribing of drugs by generic name.
This study focused on the dental disease pattern, prescribing pattern of drugs in dental OPD and utilization of antimicrobial agents. Feedback of the data along with small group discussion would help physicians to rationalise their prescribing habits. Development of antibiotic prescribing policy and therapeutic guidelines and formulary also would facilitate rational drug use.

\section{ACKNOWLEDGMENT}

The authors are grateful to Prof. S. Koirala, Vice Chancellor, for permitting this study to be carried out at B.P.Koirala Institute of Health Sciences , Nepal and Miss Sabina Shrestha, Mr. Madan Halawai, Mrs. Rusha Maskey and Mr. Gokarna Bhandari for their secretarial and technical support.

\section{REFERENCES}

1. Basnyat RT, Shrestha P . Dental caries and periodontal disease in Kathmandu. J inst Med 1991; 13:15-28

2. G'asp'ar L, V'ag'oP. Current trends in antibiotic therapy in dentistry. Fogorv $\mathrm{Sz}$ 1995; 88 (11): 355-64.

3. Fine DH, Hammond BF, Loesche WJ. Clinical use of antibiotics in Dental practice, int $\mathbf{J}$ Antimicrob Agents 1998; 9(4):235-8.

4. WHO, How to investigate drug use in health facilities: Selected drug use indicators, Geneva, World Health Organisation, WHO/ DAP/93 1993; 1:1-87.

5. Rajaratnam J, Devi S, Asirvatham $M$ et al. Prevalence and factors influencing dental problems in a rural population of Southern India .Trop Doc 1995;25: 99-100. 
6. Miura H, Araki Y, Haraguchi K, Arai Y, Umenai T. Socioeconomic factors and dental caries in developing countries: a crossnational study. Soc Sci Med 1997; 44(2):269-72.

7. Srishyla MV, Krishnamurthy M, Naga Rani MA et al. Prescription audit in an Indian Hospital setting using the DDD (Defined daily dose) concept. Indian J. pharmacol 19940;26:23-28

8. Tenenbaum H, Jehl F, Gallion C, Dahan M. Amoxicillin and clavulanic acid concentrations in gingival crevicular fluid. J Clin Periodontol 1997; 24(11):804-7.

9. Mandell GL,Petri WA Jr. Penicillins, Cephalosporins, other B-lactam Antibiotics. In: Hardman JG, Limbird LE, Molinoff PB, Ruddon RW, Gihnan AG, editors. Goodman and Gilman's the pharmacological Basis of therapeutics $9^{\text {th }}$ ed NewYork. McGraw-Hill, 1996: 1073-1101.

10. Cianco SG. Current dental chemotherapeutics. Part 2. Dent Today 1997; 16(3):48, 50.

11. Chamber HF, Sande MA. Antibmicrobial agents: general considerations. In: Hardman JG, Limbird LE, Molinoff PB , Ruddon RW, Gilman AG, editors. Goodman and Gilman's the pharmacological Basis of therapeutics ${ }^{\wedge}$ ed
NewYork. McGraw-Hill, 1996: 1029-55.

12. Epstein JB. Infective endocarditis: Dental implications and new guidelines for antibiotic prophylaxis. American Heart Association. J Can Dent Assoc 1998; 64(4):281-6.

13. Muthukrishnan A, Walters H, Douglas PS. An audit of antibiotic prescribing by general practioners in the initial management of acute dental infection. Dent update 1996, 23(8): 316-8.

14. Addy M, Renton-Harper P. Local and systemic chemotherapy in the management of periodontal disease: an opinion and review of the concept. J Oral Rebabil 1996; 23(4): 219-31.

15. Laurence Dr, Bennett PN, Brown MJ. Topics in drug therapy In; clinical pharmacology. $8^{\text {th }}$ ed. Singapore. Longman Singapore publishers (pte) Ltd, 1997: 3-36.

16. Bowden GH. Mutans streptococci caries and chlorhexidine. J Can Dent Assoc 1996; 62(9): 700, 703-7.

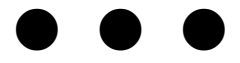

